Case Report

\title{
Intussusception of Rectosigmoid Colon Cancer Mimicking a Pedunculated Tumor
}

\author{
Susumu Saigusa, ${ }^{1,2}$ Masaki Ohi, ${ }^{1,2}$ Hiroki Imaoka, ${ }^{1,2}$ Tadanobu Shimura, ${ }^{1,2}$ \\ Yasuhiro Inoue, ${ }^{1,2}$ and Masato Kusunoki ${ }^{2}$ \\ ${ }^{1}$ Department of Surgery, Wakaba Hospital, 28-13 Minami-Chuo, Tsu, Mie 514-0832, Japan \\ ${ }^{2}$ Department of Gastrointestinal and Pediatric Surgery, 2-174 Edobashi, Tsu, Mie 514-8507, Japan \\ Correspondence should be addressed to Susumu Saigusa; saigusa@wakabahsp.jp
}

Received 11 March 2014; Accepted 30 April 2014; Published 13 May 2014

Academic Editor: Sigmund H. Ein

Copyright (C) 2014 Susumu Saigusa et al. This is an open access article distributed under the Creative Commons Attribution License, which permits unrestricted use, distribution, and reproduction in any medium, provided the original work is properly cited.

\begin{abstract}
Intussusception in adults is a rare phenomenon involving the colon in approximately $20 \%$ of cases. A 65 -year-old man was hospitalized with anorexia, anemia, dehydration, and melena. Digital rectal examination revealed a palpable mass approximately $5 \mathrm{~cm}$ from the anal verge. The mass moved between the rectosigmoid colon and the rectum below the peritoneal reflection during radiographic examinations and during sigmoidoscopy. We strongly suspected a rectosigmoid pedunculated tumor and performed a low anterior resection. Intraoperatively we observed intussusception of the rectosigmoid colon with easy manual reduction. The tumor was palpable in the rectosigmoid colon. The postoperative course was uneventful. This case illustrates intussusception of a rectosigmoid type 1 colon adenocarcinoma mimicking a pedunculated tumor.
\end{abstract}

\section{Introduction}

Intussusception is defined as the telescoping of a proximal segment of the gastrointestinal tract into the distal lumen. Intussusception in adults is a rare condition, with colonic intussusception accounting for approximately $20 \%$ of the cases [1-3]. Previous reports indicate that computed tomography (CT) is the most sensitive diagnostic modality for intussusception $[2,4]$. However, preoperative diagnostic rate is variable $[2,3,5-7]$. Adult intussusception is therefore a challenging diagnostic problem for surgeons.

\section{Case Report}

A 65-year-old man was hospitalized with appetite loss, anemia, and dehydration. His medical history was significant for alcoholism and gout. Eight days after admission, he had melena without abdominal pain. Laboratory investigation at the time of admission revealed anemia (hemoglobin $9.6 \mathrm{~g} / \mathrm{dL}$ ), hyperuricemia (uric acid $11.0 \mathrm{mg} / \mathrm{dL}$ ), dehydration (blood urea nitrogen $36 \mathrm{mg} / \mathrm{dL}$, creatinine $1.0 \mathrm{mg} / \mathrm{dL}$, and creatine kinase $1790 \mathrm{IU} / \mathrm{l}$ ), mild inflammation (Creactive protein $3.41 \mathrm{mg} / \mathrm{dL}$ ), and elevated liver enzymes (aspirate aminotransferase $153 \mathrm{IU} / \mathrm{l}$, alanine aminotransferase $119 \mathrm{IU} / \mathrm{l})$. Abdominal X-ray was unremarkable (Figure 1). After the occurrence of melena, digital rectal examination revealed a palpable mass approximately $5 \mathrm{~cm}$ from the anal verge. Sigmoidoscopy revealed a mobile tumor occupying the lumen $15 \mathrm{~cm}$ from anal verge, the proximal side of which could not be visualized (Figures 2(a) and 2(b)). Biopsy revealed well-differentiated adenocarcinoma. Gastrografin enema and initial CT showed that the tumor was in the rectosigmoid colon (Figures 2(c) and 3(a)). Subsequent contrast-enhanced CT showed that the tumor shifted into the rectum below the peritoneal reflection with no evidence of distant metastasis (Figure 3(b)). The patient did not have any obstructive symptoms. We strongly suspected a rectosigmoid pedunculated tumor. After informed consent, definitive surgery was performed. Operative findings confirmed intussusception of the rectosigmoid colon with easy manual reduction (Figure 4(a)). The tumor was palpable in the 


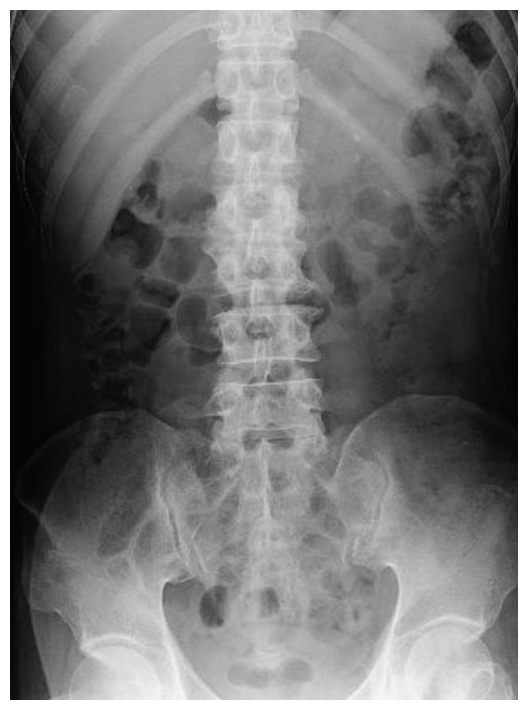

FIGURE 1: Preoperative abdominal X-ray.

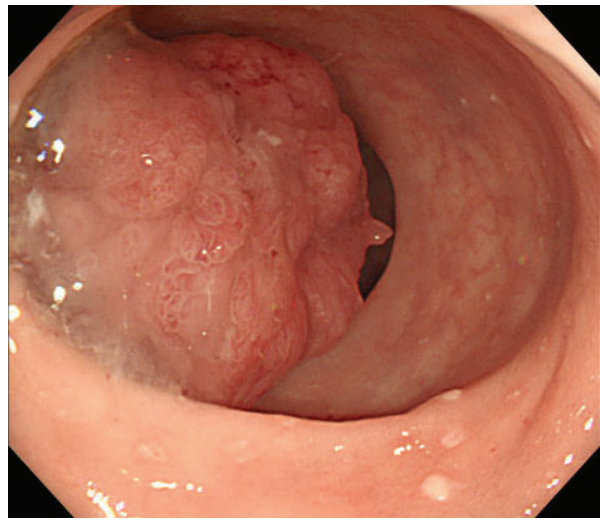

(a)

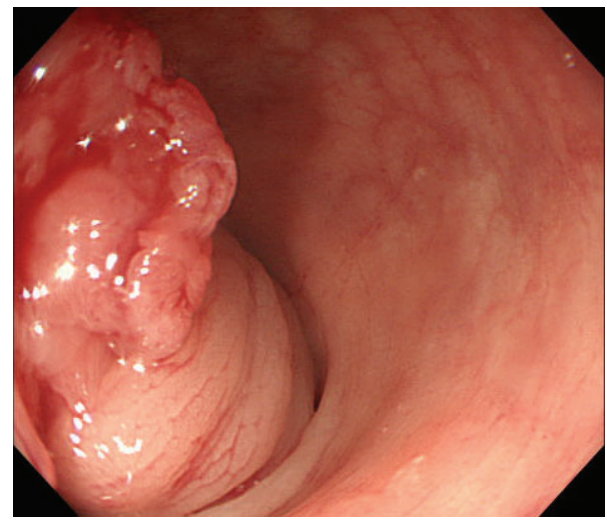

(b)

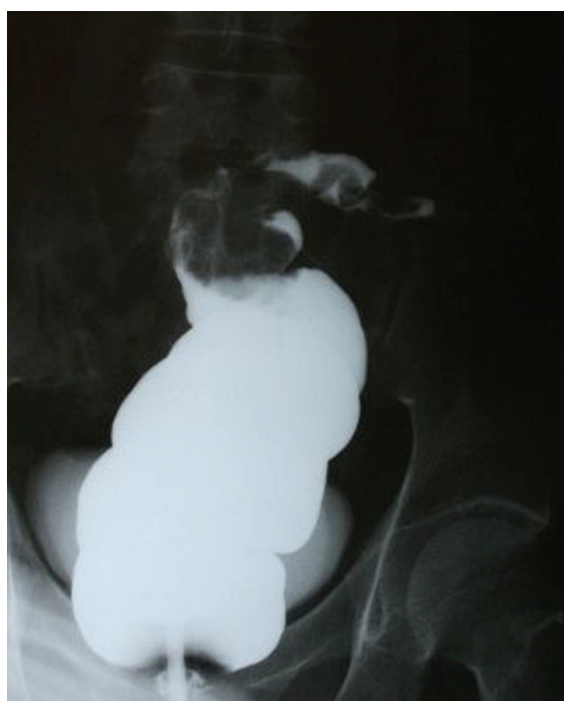

(c)

FIGURE 2: Sigmoidoscopy revealed a tumor occupying the lumen $15 \mathrm{~cm}$ from anal verge (a). The bowel mucosa proximal mobile tumor was observed although the camera could not traverse beyond the lesion (b). Gastrografin enema demonstrating the tumor in the rectosigmoid colon without the typical coiled-spring appearance or cup-shape filling defect (c). 


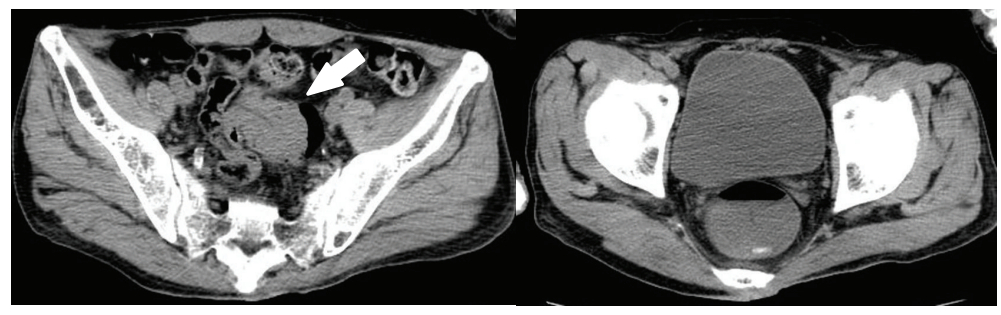

(a)

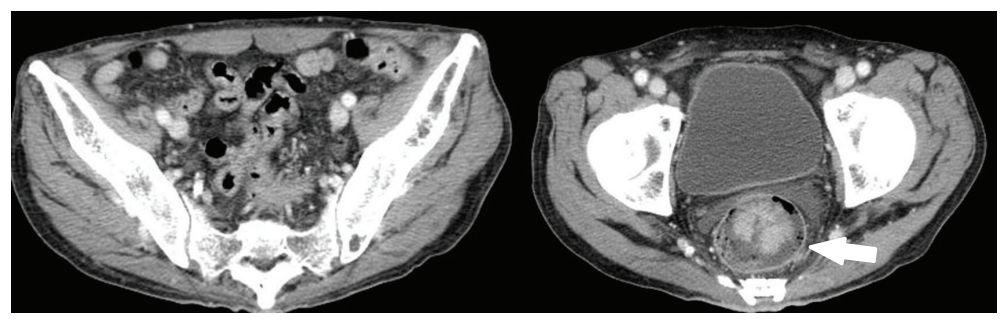

(b)

FIGURE 3: Initial CT showed the tumor located in the rectosigmoid colon (a). Preoperative contrast-enhanced CT showed that the tumor shifted to rectum below the peritoneal reflection (b).

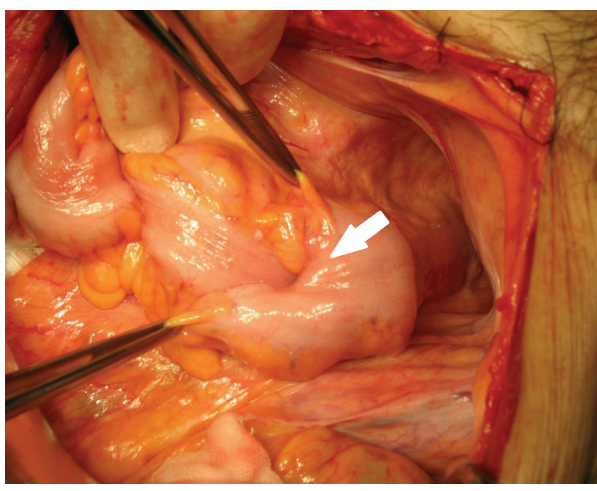

(a)

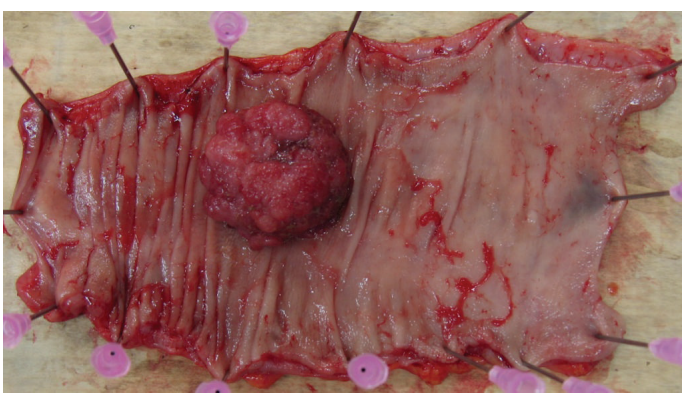

(c)

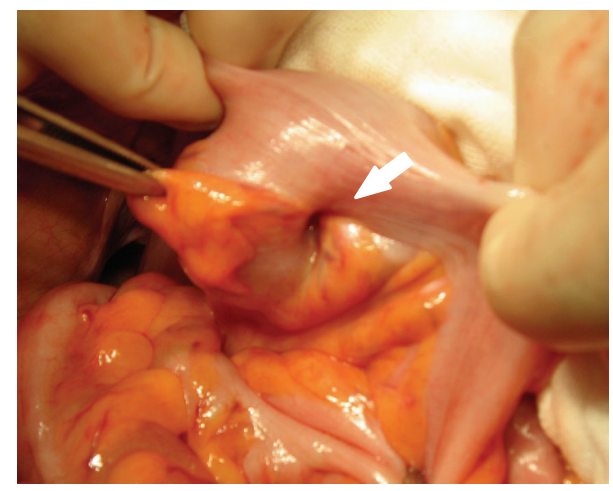

(b)

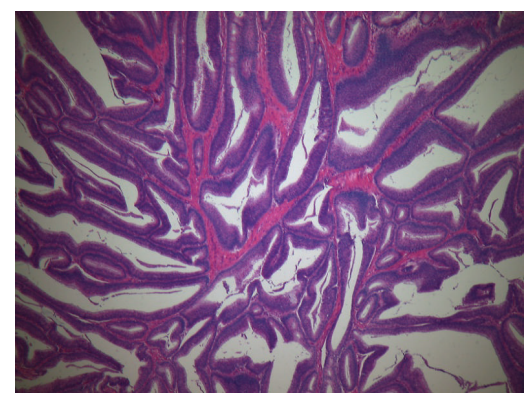

(d)

FIGURE 4: Intussusception of the rectosigmoid colon (a). Suspected area of subserosal invasion (b). Resected specimen with type 1 tumor (35 $\times 40 \mathrm{~mm}$ ) (c). Pathological examination revealed a well-differentiated adenocarcinoma with subserosal invasion. Original magnification 40x (d).

rectosigmoid colon (Figure 4(b)). A low anterior resection with a stapled anastomosis was performed. Histopathological examination revealed a $4 \mathrm{~cm}$, T3N0 M0 (stage II), welldifferentiated adenocarcinoma (Figures 4(c) and 4(d)). The patient's postoperative course was uneventful.

\section{Discussion}

The rate of preoperative diagnosis of intussusception has improved with advancement of imaging studies but continues to be challenging $[2,3,5-7]$. Previous reports indicate that CT 
is the most sensitive diagnostic modality for intussusception $[2,4]$. However, preoperative CT did not reveal the typical appearance of intussusception such as a pseudokidney or target sign in our case. The intussusception in our case had spontaneously reduced, and our intraoperative observation confirmed that it was easily repositioned by traction of the proximal colon.

Several authors have reported laparoscopic management of sigmoidorectal intussusception [8-10]. Greenley et al. indicated that an extra skill set is needed to reduce the intussuscepted segment of colon without violating the lumen of the bowel in sigmoidorectal intussusception and that a combined laparoscopic and perineal attempt at reduction followed by resection is justified if there is no evidence of bowel necrosis, inflammation, or tumor invasion [10]. En bloc resection without reduction is recommended for colonic intussusception [11-13] as colonic intussusception is more likely to have a malignant etiology $[2,14,15]$ and bowel injury including perforation in malignant cases has a high risk of cancer cell dissemination [1]. We performed laparotomy but not laparoscopic approach in the present case because we suspected a pedunculated tumor moving into the rectum and wanted to confirm the tumor location by direct palpation.

Macroscopic and pathological features of intussusception caused by colon adenocarcinoma of the colon have not been well evaluated. Several reports have shown that the lead points of colonic intussusception were mostly due to villous or type 1 (protruded type; Bormann's classification type 1) tumors $[10,16-20]$. Chen et al. reported synchronous double colocolic intussusception and that both adenocarcinomas revealed macroscopic type 1 or villous adenocarcinomas with subserosal invasion [21]. In the present case report, we also found that type 1 adenocarcinoma with subserosal invasion resulted in colonic intussusception. Warshauer and Lee indicated that neoplastic lead points were significantly longer and larger in diameter than nonneoplastic ones [22]. Taken together, colonic intussusception may be due to large macroscopic type 1 or villous tumors.

In conclusion, intussusception of rectosigmoid colon adenocarcinoma can mimic a pedunculated tumor. Preoperative diagnosis of intussusception with spontaneous reduction is challenging.

\section{Consent}

Written informed consent was obtained from the patient for publication of this case report.

\section{Conflict of Interests}

Susumu Saigusa and the coauthors have no conflict of interests regarding the publication of this paper.

\section{References}

[1] T. Azar and D. L. Berger, "Adult intussusception," Annals of Surgery, vol. 226, no. 2, pp. 134-138, 1997.
[2] J. Y. M. Chiang and Y. S. Lin, "Tumor spectrum of adult intussusception," Journal of Surgical Oncology, vol. 98, no. 6, pp. 444-447, 2008.

[3] A. Marinis, A. Yiallourou, L. Samanides et al., "Intussusception of the bowel in adults: a review," World Journal of Gastroenterology, vol. 15, no. 4, pp. 407-411, 2009.

[4] G. Gayer, R. Zissin, S. Apter, M. Papa, and M. Hertz, "Adult intussusception-a CT diagnosis," The British Journal of Radiology, vol. 75, no. 890, pp. 185-190, 2002.

[5] L. K. Eisen, J. D. Cunningham, and A. H. Aufses Jr., "Intussusception in adults: institutional review," Journal of the American College of Surgeons, vol. 188, no. 4, pp. 390-395, 1999.

[6] H. A. M. Reijnen, H. J. M. Joosten, and H. H. M. De Boer, "Diagnosis and treatment of adult intussusception," The American Journal of Surgery, vol. 158, no. 1, pp. 25-28, 1989.

[7] F. J. Morera-Ocón, E. Hernández-Montes, and J. C. BernalSprekelsen, "Intestinal invagination in adults: presentation of a case and a review of the Spanish literature," Cirugia Espanola, vol. 86, no. 6, pp. 358-362, 2009.

[8] K. J. Park, H. J. Choi, S. H. Kim et al., "Sigmoidorectal intussusception of adenoma of sigmoid colon treated by laparoscopic anterior resection after sponge-on-the-stick-assisted manual reduction," World Journal of Gastroenterology, vol. 12, no. 1, pp. 146-149, 2006.

[9] C. H. Chuang, C. B. Hsieh, C. H. Lin, and J. C. Yu, "Laparoscopic management of sigmoid colon intussusception caused by a malignant tumor: case report," Revista Espanola de Enfermedades Digestivas, vol. 99, no. 10, pp. 615-616, 2007.

[10] C. T. Greenley, B. Ahmed, L. Friedman, L. Deitte, and Z. T. Awad, "Laparoscopic management of sigmoidorectal intussusception," Journal of the Society of Laparoendoscopic Surgeons, vol. 14, no. 1, pp. 137-139, 2010.

[11] J. G. Martín-Lorenzo, A. Torralba-Martinez, R. Lirón-Ruiz et al., "Intestinal invagination in adults: preoperative diagnosis and management," International Journal of Colorectal Disease, vol. 19, no. 1, pp. 68-72, 2004.

[12] N. Erkan, M. Haciyanli, M. Yildirim, H. Sayhan, E. Vardar, and A. F. Polat, "Intussusception in adults: an unusual and challenging condition for surgeons," International Journal of Colorectal Disease, vol. 20, no. 5, pp. 452-456, 2005.

[13] B. K. P. Goh, H. M. Quah, P. K. H. Chow et al., "Predictive factors of malignancy in adults with intussusception," World Journal of Surgery, vol. 30, no. 7, pp. 1300-1304, 2006.

[14] D. G. Begos, A. Sandor, and I. M. Modlin, "The diagnosis and management of adult intussusception," The American Journal of Surgery, vol. 173, no. 2, pp. 88-94, 1997.

[15] E. L. Felix, M. H. Cohen, A. D. Bernstein, and J. H. Schwartz, "Adult intussusception. Case report of recurrent intussusception and review of the literature," The American Journal of Surgery, vol. 131, no. 6, pp. 758-761, 1976.

[16] L. Ho and L. D. Rosenman, "Complete invagination of the vermiform appendix with villous adenoma, intussuscepting to the splenic flexure of the colon," Surgery, vol. 77, no. 4, pp. 505506, 1975.

[17] S. Sadahiro, T. Ohmura, Y. Yamada, T. Saito, and S. Akatsuka, "A case of cecocolic intussusception with complete invagination and intussusception of the appendix with villous adenoma," Diseases of the Colon and Rectum, vol. 34, no. 1, pp. 85-88, 1991.

[18] K. S. Tonsekar, R. Cacdac, R. Ashare, and J. H. Libcke, "Villous adenoma of the vermiform appendix with cecal intussusception: a case report and review of literature," The American Surgeon, vol. 60, no. 12, pp. 982-984, 1994. 
[19] Y. Fujii, N. Taniguchi, and K. Itoh, "Intussusception induced by villous tumor of the colon: sonographic findings," Journal of Clinical Ultrasound, vol. 30, no. 1, pp. 48-51, 2002.

[20] N. Wang, X. Y. Cui, Y. Liu et al., "Adult intussusception: a retrospective review of 41 cases," World Journal of Gastroenterology, vol. 15, no. 26, pp. 3303-3308, 2009.

[21] C. W. Chen, C. W. Lai, and K. H. Hsiao, "Synchronous adenocarcinomas of the colon presenting as synchronous colocolic intussusceptions in an adult," World Journal of Surgical Oncology, vol. 10, article 272, 2012.

[22] D. M. Warshauer and J. K. T. Lee, "Adult intussusception detected at CT or MR imaging: clinical-imaging correlation," Radiology, vol. 212, no. 3, pp. 853-860, 1999. 


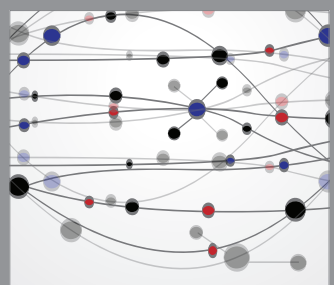

The Scientific World Journal
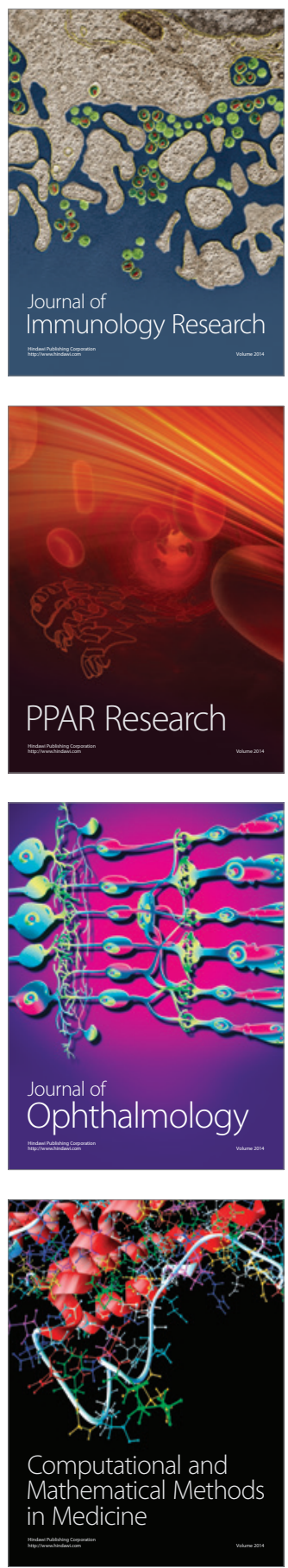

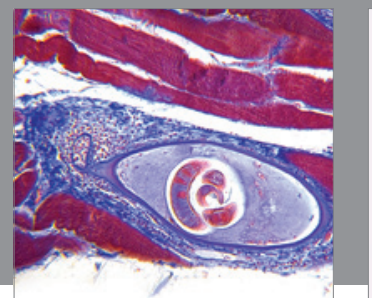

Gastroenterology

Research and Practice
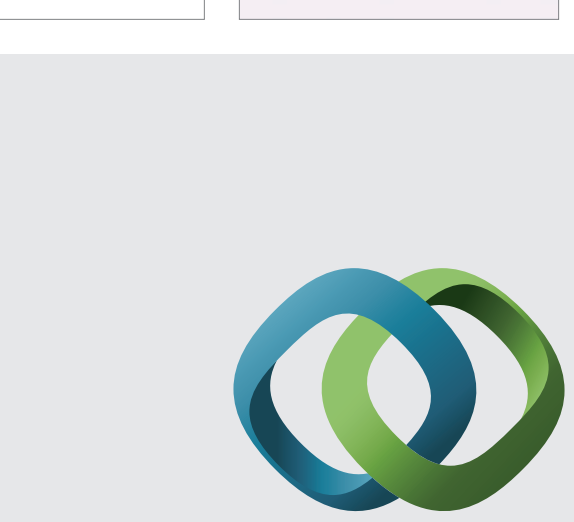

\section{Hindawi}

Submit your manuscripts at

http://www.hindawi.com
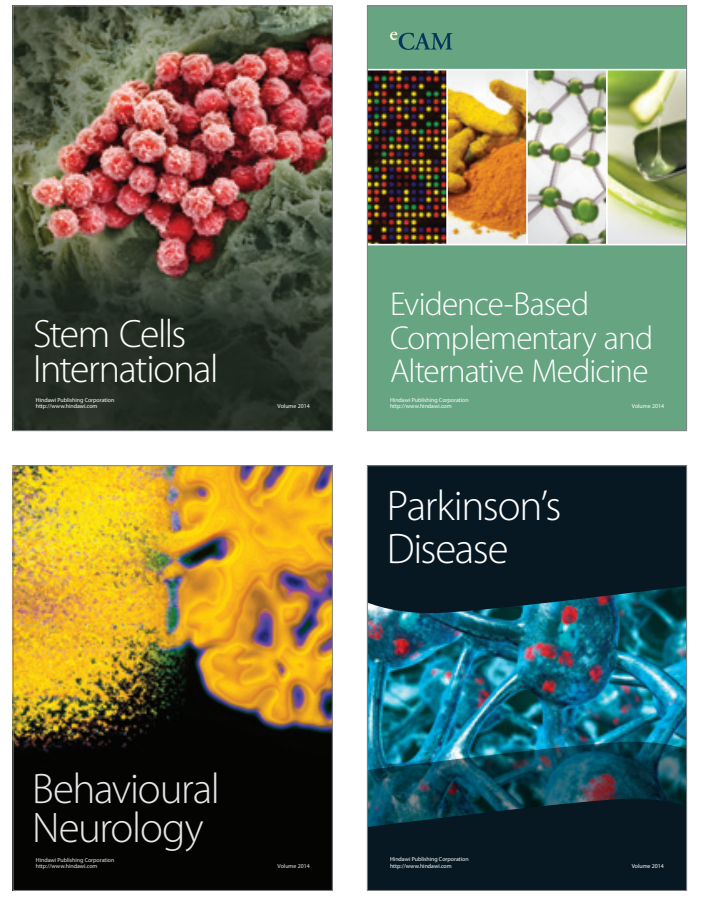
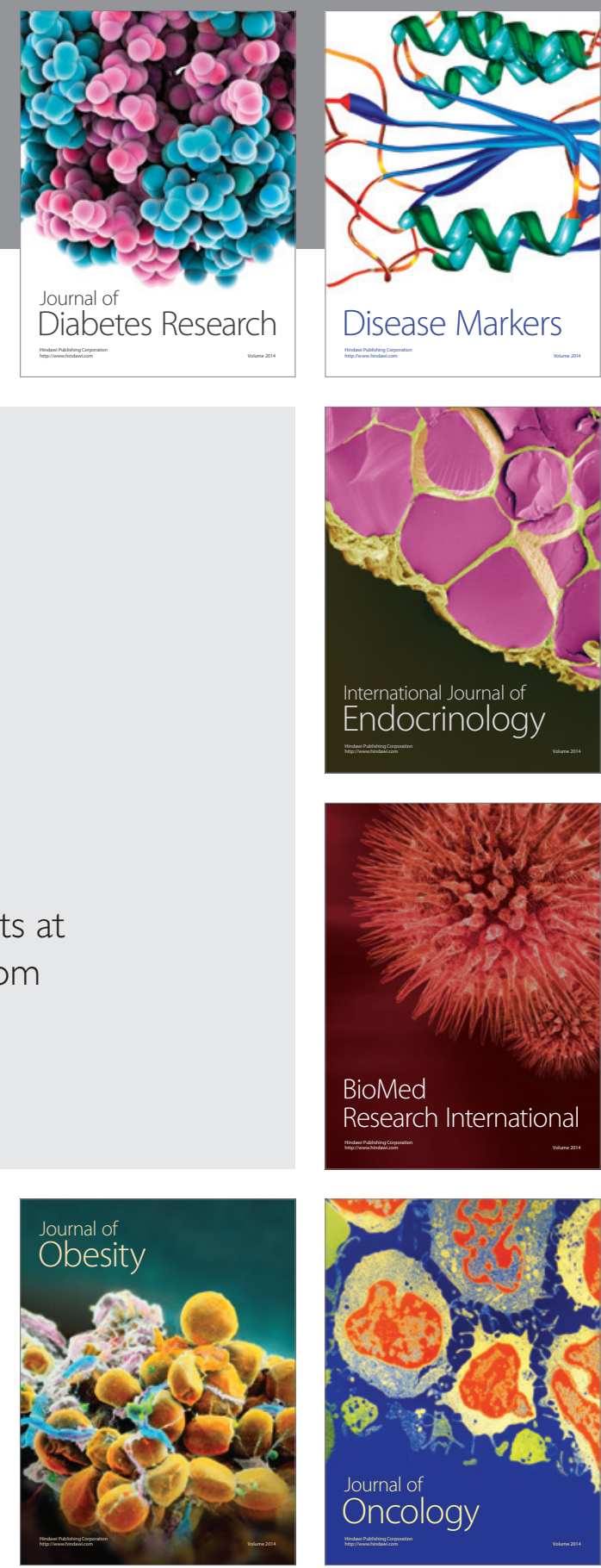

Disease Markers
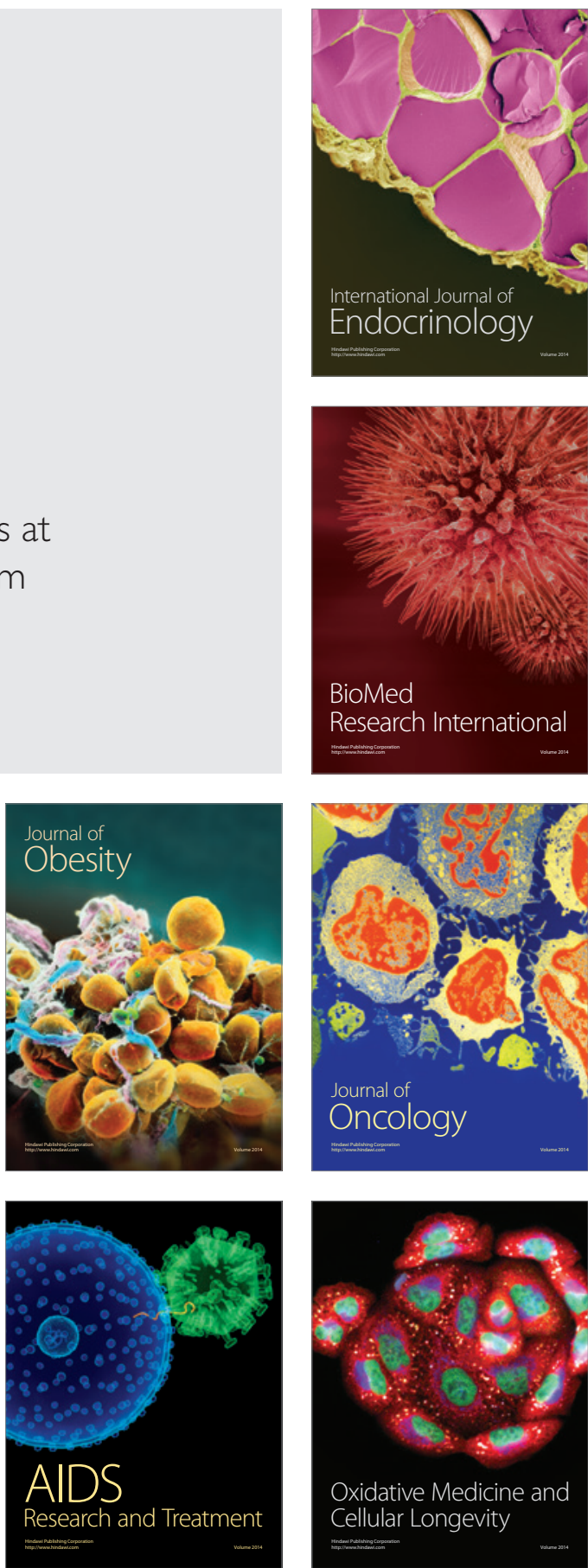